\title{
Self-Verification Strivings in Children Holding Negative Self-Views: The Mitigating Effects of a Preceding Success Experience
}

\author{
Albert Reijntjes $\cdot$ Sander Thomaes $\cdot$ \\ Jan Henk Kamphuis • Bram Orobio de Castro • \\ Michael J. Telch
}

Published online: 3 January 2010

(c) The Author(s) 2009. This article is published with open access at Springerlink.com

\begin{abstract}
Research among adults has consistently shown that people holding negative self-views prefer negative over positive feedback. The present study tested the hypothesis that this preference is less robust among preadolescents, such that it will be mitigated by a preceding positive event. Pre-adolescents $(n=75)$ holding positive or negative global self-esteem were randomized to a favorable or unfavorable peer evaluation outcome. Next, preferences for positive versus negative feedback were assessed using an unobtrusive behavioral viewing time measure. As expected, results showed that after being faced with the success outcome children holding negative selfviews were as likely as their peers holding positive selfviews to display a significant preference for positive feedback. In contrast, children holding negative self-views displayed a stronger preference for negative feedback after being faced with the unfavorable outcome that matched their pre-existing self-views.
\end{abstract}

Keywords Self-verification - Negative self-views . Feedback seeking - Self-discrepant feedback · Preadolescent children

\author{
A. Reijntjes $(\square)$ \\ Department of Psychosocial Development in Context, \\ Utrecht University, PO Box 80150, Utrecht, The Netherlands \\ e-mail: a.h.a.reijntjes@uu.nl \\ S. Thomaes - B. O. de Castro \\ Developmental Psychology, Utrecht University, \\ PO Box 80150, Utrecht, The Netherlands \\ J. H. Kamphuis \\ University of Amsterdam, Amsterdam, The Netherlands \\ M. J. Telch \\ The University of Texas at Austin, Austin, TX, USA
}

\section{Introduction}

The social feedback children receive from significant others has a pervasive influence on their social development (e.g., Bowlby 1980; Cole et al. 2001; Harter 2006). Whereas children who receive frequent positive information about themselves are likely to develop positive selfviews, those who receive recurring negative feedback tend to develop or maintain less favorable self-views (e.g., Bowlby 1980; Harter 2006). Importantly, however, children are not merely passive recipients of the feedback they obtain from others. Rather, they seek out and prefer some types of feedback over others.

According to self-verification theory (Swann 1983, 1990; Swann et al. 2002), self-views play a central role in the kinds of social feedback people seek out. The theory asserts that people work to confirm their firmly held selfviews, even when they are negative. That is, people holding negative self-views are preferentially (but not exclusively) drawn to negative feedback because such selfconfirming feedback bolsters confidence in the accuracy of negative self-views (i.e., "epistemic" reasons) and serves to avoid the negative consequences resulting from others forming overly positive appraisals (i.e., pragmatic reasons).

Among adults, the linkage between negative self-views and feedback seeking has been examined extensively. A series of studies (e.g., Swann et al. 1992, 1992) has provided robust empirical support for self-verification theory's assertion that negative self-views consistently lead people to prefer negative over positive self-relevant feedback. For instance, Swann and colleagues observed that college students holding negative self-views, compared to those holding positive self-views preferred friends who evaluated them negatively, were more inclined to seek negative than positive feedback from their roommates, and preferentially 
solicited unfavorable feedback from their dating partners (Swann et al. 1992). Moreover, participants scoring high in depressive symptoms as well as clinically depressed adults were more likely than controls to choose interacting with someone who appraised them negatively over the opportunity to avoid the encounter (Giesler et al. 1996; Swann et al. 1992).

Interestingly, Swann et al. (1992) also showed that after being faced with self-discrepant positive feedback-feedback that threatened the subjective validity of their negative self-views-dysphoric participants subsequently preferred to receive feedback about their limitations. In contrast, non-dysphoric participants faced with self-discrepant negative evaluations preferred to receive feedback about their strengths. It thus appears that after being presented with self-discrepant positive feedback, dysphorics compensated for threats to their self-views by displaying a preference for negative feedback that likely served to reaffirm their low self-esteem. Consistent with this argument, in a study examining the spontaneous verbalizations of adults as they chose interaction partners (Swann et al. 1992), participants with negative self-views chose unfavorable partners predominantly for the epistemic reasons put forth by self-verification theory (e.g., "I feel more at ease with someone who can judge me for what I am").

Relative to adults, few studies have examined the linkage between negative self-views and feedback seeking in children. Using a sample of children that were psychiatric inpatients at an academic medical center, Joiner et al. (1997) showed that as children's depression level increased, so did their self-reported preferences for receiving negative feedback. These findings were obtained using a questionnaire assessing feedback preferences in four distinct self-relevant domains (i.e., social, intellectual, athletic, and physical attractiveness). Two studies using a comparable methodology with community samples (Borelli and Prinstein 2006; Cassidy et al. 2003a, b) indicated that the tendency for children higher in depression and lower in global self-worth to prefer more negative feedback extends to non-clinical samples.

A similar link between children's self-views and their selection of peers was observed by Cassidy et al. (2003a) in a study conducted among third and seventh graders. Specifically, findings revealed that children reporting negative self-views on specific competence domains (e.g., sports) were significantly more likely than their counterparts to display an interest in meeting a peer who evaluated them negatively on that domain. Interestingly, results provided preliminary evidence to suggest that self-verification strivings may be more pronounced among third graders, relative to seventh graders.

Unfortunately, the peer selection and feedback seeking preferences of children holding negative self-views are likely to maintain and/or exacerbate their negative selfviews. That is, to the extent that children holding negative self-views preferentially seek out negative feedback and peers who appraise them negatively, their negative selfviews are likely further strengthened and internalized.

However, a recent study by Reijntjes et al. (2007) examining the linkage between depressive symptoms and feedback preferences among pre-adolescents provided preliminary evidence that children holding negative selfviews may not always be more inclined than their peers to eschew positive feedback and undermine opportunities to improve their self-views. In this study, participants were first presented with a self-congruent or a self-discrepant global evaluation outcome and then self-reported feedback preferences (positive versus negative) were assessed. After being faced with an unfavorable self-congruent outcome, children displaying higher levels of depressive symptoms showed a stronger preference for more negative feedback, relative to their peers. In contrast, after receiving the selfdiscrepant success outcome children high in depressive symptoms were as likely as their peers low in depression to express a significant preference for positive feedback.

What may account for this interesting pattern of findings? We suggest that the motive to preferentially sample unfavorable feedback for the epistemic reasons specified by self-verification theory (i.e., corroborative feedback bolsters individuals' confidence in the accuracy of their self-views and promotes intra-psychic coherence) may be weaker for children than for adults. It is only from late childhood that children become able to make global evaluations of themselves (e.g., "I am a worthless person") that are at the core of negative self-views (e.g., Harter 2006). Hence, relative to adults, pre-adolescents' negative selfviews are less likely to be ingrained and crystallized into chronic states of self-doubt and self-derogation.

In line with this reasoning, a recent meta-analysis examining the stability of self-esteem across the life span showed that during late childhood and early adolescence self-esteem is more unstable than in any other developmental period (Trzesniewski et al. 2003). Because of this instability of children's self-views, the self-discrepant success feedback may have temporarily suspended their negative self-views, which in turn may have attenuated efforts to verify their negative self-views with confirming negative feedback. Stated differently, we hypothesize that in a positive evaluative context children holding negative self-views are not strongly inclined to subsequently eschew positive feedback that is at odds with their negative self-views, because the favorable feedback is unlikely to engender the feeling that they may not know themselves well, thereby threatening their identity (feelings of "existential security").

Although the findings of the Reijntjes et al. (2007) study are at odds with predictions from self-verification theory, no 
firm conclusion can be drawn. First, feedback preferences were assessed using a forced-choice self-report item asking participants to indicate their preference for receiving favorable versus unfavorable feedback. However, selfreported feedback preferences may diverge from actually displayed feedback seeking preferences. For instance, according to the "immediate capitalization/later shifting" hypothesis advanced by Casbon et al. (2005), immediately subsequent to receiving positive feedback individuals holding negative self-views may seek further positive feedback to foster the affective satisfaction evoked by the self-enhancing feedback and only later, after realizing that such feedback contradicts one's self-views, shift to more negative feedback seeking. Several studies among adults have provided support for this argument (Swann et al. 1990; Hixon and Swann 1993), by showing that when people holding negative self-views are afforded more time to reflect on themselves, they are more likely to display a preference for negative self-verifying feedback. Hence, the dynamic social reality in which the feedback children receive may influence their subsequent feedback seeking is likely better captured by assessing actually obtained feedback over time.

Second, no effort was made to compare children holding strongly positive versus strongly negative self-views. Specifically, Swann has argued (e.g., Swann 1990; Swann et al. 1992) that the role of self-views should be examined by contrasting individuals whose self-views are strongly positive and strongly negative (e.g., those with scores in the top and bottom $20 \%$ of a large sample; see also Cassidy et al. 2003a, b). However, by examining all participants, also those with intermediate levels of self-views, no extreme groups were contrasted. Moreover, although negative self-views are an important feature of depression (e.g., Beck 1967), a more direct index of children's self-views is their sense of global self-worth (general self-esteem).

The present study was designed to test the hypothesis that the preference for negative feedback among children holding negative self-views will be significantly attenuated when their feedback seeking is assessed in the context of a social success experience, relative to a failure experience that primes their pre-existing negative self-views. Preadolescents were examined because self-esteem is least stable in this developmental period. To maximize the contrast between children holding positive versus negative selfviews, following Cassidy et al. (2003a, b), children scoring in the upper and lower quintile on a widely used measure of general self-esteem comprised the positive versus negative self-view groups. Participants were first presented with an experimentally manipulated global peer evaluation outcome that was either positive or negative. Subsequently, an unobtrusive behavioral viewing time measure was employed to assess participants' preference for positive versus negative self-relevant feedback during a fixed $5 \mathrm{~min}$ period. We expected that children holding negative selfviews would display a significantly stronger interest in positive feedback when faced with the favorable evaluation outcome than they would after receiving the unfavorable evaluation outcome. In contrast, we expected that children holding positive self-views would display a robust preference for positive feedback across both outcomes.

\section{Method}

\section{Participants}

Participants ( $N=75 ; 51 \%$ boys) were children enrolled in 5 th and 6th grade classes from public elementary schools in the Netherlands. These children scored in the upper and lower quintiles of the subscale of the Perceived Competence Scale for Children (PCSC; Harter 1982) tapping global self-worth. They were predominantly Caucasian $(84 \%)$, and ranged in age from 10 to 12 years $(M=10.9$, $\mathrm{SD}=.84$ ). Participants were recruited from an initial sample of 278 children for whom classroom teachers sent parent permission letters home. Of the 244 letters returned, 192 parents $(79 \%)$ gave their consent for their children to participate in the study, and $52(21 \%)$ declined. We also obtained IRB approval and permission to conduct the study from the school principal and each child's teacher. Children received a small gift (e.g., mechanical pencils, markers) for their participation.

\section{Procedure}

\section{Screening}

During a pre-test session at the beginning of the semester all participants completed the global self-esteem subscale of the Perceived Competence Scale for Children (see "Measures") in their regular classrooms during school hours. During administration of the measures the teacher remained in the classroom. Children were informed that they could discontinue their participation at any time. A research assistant read the directions aloud and children were encouraged to ask for help if they had questions or encountered problems completing the questionnaires. Children scoring in the upper and lower quintiles of the measure were classified as the positive and negative selfviews groups, respectively.

\section{Survivor Contest}

The subsequent experimental session was carried out approximately 2 weeks (range $10-17$ days, $M=13.8$, $\mathrm{SD}=4.2$ ) after screening and was carried out individually 
in a quiet room on the school grounds. Participants were told that they would take part in an Internet computer-contest called 'Survivor'. In reality, the contest was a computer program written in Visual Basic designed to present the illusion of playing on-line with four other children.

Upon arrival, the participant was seated in front of a laptop computer. Their photo was taken by a web-cam connected to the laptop. Participants were informed that their pictures would be uploaded so that the other contestants could view their photos online. The objective and rules of the contest were presented on screen. Participants were informed that they would be playing against four owngender contestants of comparable age (all of them were fictitious co-players) from four different schools in the same area, and that all participants would be evaluated by a panel of judges consisting of 16 peers, eight boys and eight girls. Specifically, participants were explained that each judge would give them a score between 0 and 100, with higher scores reflecting higher levels of perceived likeability.

Next, participants were directed through a series of screens in which they were asked to answer a series of questions about themselves to help the judges and the other contestants learn more about them. Questions pertained to their favorite musical group, future occupation, things they liked and disliked about themselves. Using 5-point Likert scales, participants also provided self-ratings of several character traits (e.g., sense of humor, agreeableness), how they got along with other children, and their academic performance. Participants were informed on screen that their picture along with their answers to the personal questions would be posted on the Internet and viewed by the judges who would then give them a "likeability" score ranging from 0 to 100 . Moreover, children were informed that each judge would also provide concrete feedback, in the form of brief descriptions of what they liked or disliked about each participant.

Next, participants were informed that the computer would now tally the judges' scores for each contestant. After a $5 \mathrm{~s}$ waiting period, the names of the players with the highest and the lowest score appeared in capital letters on the screen. In the success condition, the name of the participant was displayed as having obtained the highest total score; one randomly chosen alleged co-player's name appeared as having obtained the lowest total score. Conversely, in the failure condition the name of the participant was displayed as having obtained the lowest total score, while one alleged co-player's name appeared as having obtained the highest total score.

\section{Post-Evaluation Behavioral Assessment of Feedback Preferences}

After receiving the evaluation-outcome, an announcement appeared on screen informing participants that they would now have $5 \mathrm{~min}$ to look over the feedback that the judges had written about them. Participants were further informed that they could spend as little or as much time as they wanted on the feedback from any given judge, and that they were also free to determine the sequence of viewing the feedback from the judges. Upon clicking "continue" an overview screen appeared containing pictures of all 16 judges (eight boys and eight girls), together with the likeability scores they had allegedly given the participant. Regardless of their assigned peer evaluation outcome condition (i.e., success or failure), eight of the judges (four boys and four girls) allegedly rated the participant favorably (i.e., assigned a high likeability score, $M=80$, range 75-85), whereas the other eight judges (four boys, four girls) rated the participant unfavorably (i.e., assigned a low likeability score, $M=40$, range 35-45). By clicking on the picture of a targeted peer judge, a separate screen appeared displaying the profile of the peer judge. This profile contained basic personal information (i.e., name, age, and residence) as well as positive or negative feedback about the participant. This feedback-the specific remarks differed across judges-always consisted of four brief evaluative statements that were presented as a brief narrative. In the case of judges that had allegedly provided a high likeability score, these statements were all positive (e.g., "I would like to be friends with this person", "(s)he seems to be a pleasant person", "(s)he seems witty", "(s)he seems fun to hang out with"). Conversely, for judges that had allegedly provided a low likeability score, the valence of these statements was reversed (e.g., "I would not like to be friends with this person", "(s)he seems to be an unpleasant person", "(s)he does not seem witty", "(s)he does not seem fun to hang out with"). All participants were presented the same 16 peer judge profiles, 8 of which were favorable, and 8 were unfavorable. All judges provided three general comments (e.g., "I would not like to be friends with this person") and one more domain-specific remark (e.g., "she does not seem witty"). By clicking on the appropriate buttons, participants could move back and forth between the overview screen and the individual profiles of each of the 16 judges.

During the 5 min viewing time period, time spent viewing the profiles of each of the 16 peer judges (in seconds) was unobtrusively recorded by computer. All $300 \mathrm{~s}$ are spent either looking at positive or negative feedback; the clock paused when participants looked at the overview screen. At the end of this viewing period, the participant was accompanied to an adjacent room where then a research assistant debriefed the child thoroughly (for a detailed description of ethical considerations, see Thomaes et al. in press). 
Measures

\section{Dutch Version of the Perceived Competence Scale for Children (Harter 1982)}

The PCSC Global Self-Esteem subscale (Harter 1982) is a 6-item measure to assess children's global self-esteem. For each item, the child is presented two statements (e.g., 'some children are satisfied with their life as it is' versus 'other children are not satisfied with their life as it is') and asked to choose the one that best describes him or her. Subsequently, the participant rates the relevant statement as 'Entirely true of me' or 'Somewhat true of me'. That choice is then rated on a 4-point scale ranging from 1 (lowest self-worth) to 4 (highest self-worth). The Dutch version of the PCSC has demonstrated adequate internal consistency, test-retest reliability and discriminant validity (Veerman et al. 1996). Coefficient alpha in the present sample was .83. Total scores ranged from 8 to 24 . Scores did not differ as a function of age, gender, or their interaction.

\section{Behavioral Assessment of Time Spent Viewing Positive Versus Negative Feedback}

During the $5 \mathrm{~min}$ viewing time period, time spent (in seconds) viewing the feedback of each of the 16 peer judges was recorded by computer. As noted, regardless of the assigned peer evaluation outcome eight judges provided high likeability scores, along with the positive feedback remarks. In turn, the other eight judges provided low likeability scores along with the negative feedback remarks.

\section{Power Considerations}

Power analyses were performed using the G 3 Power program (Erdfelder et al. 1996). With alpha set at .05, our sample size of 75 yields adequate power (.8) to detect a moderate effect size $(f=.33)$ for the critical evaluation outcome by self-view status interaction term.

\section{Results}

\section{Preliminary Analyses}

Analyses revealed that time spent viewing positive and negative feedback was not related to the number of positive or negative judges that were reviewed. Regardless of condition and self-worth status, participants spent time viewing the feedback of most judges. For unfavorable judges, the mean number of profiles viewed (out of 8 ) was $6.75(\mathrm{SD}=1.72$; for favorable judges this figure was 7.25
$(\mathrm{SD}=1.26)$. Regardless of self-worth status and the valence of the feedback, both male and female participants spent more time viewing profiles of same-gender judges, relative to opposite-gender judges ( $p$ 's $<.05$ ).

Significant differences emerged with respect to the ratings of personal information that participants provided to the judges as a function of self-worth status. Specifically, participants in the low self-worth group endorsed lower ratings for sense of humor and how well they got along with other children, relative to their counterparts high in self-worth $(p$ 's <.05). Moreover, children low in selfworth were somewhat more likely to report not yet being sure about their future occupation $(p<.10)$. These findings were not moderated by gender. For all other questions, no differences as a function of self-view status or gender emerged.

\section{Equivalence of the Experimental Groups}

Children in both self-view groups (positive versus negative) were randomly assigned to one of the experimental conditions. As intended, children in the high self-view group $(n=40)$ reported significantly higher global selfesteem scores $(M=23.50, \mathrm{SD}=.51)$ than their counterparts $(n=35)$ in the low self-view group $(M=13.46$, $\mathrm{SD}=2.37) ; F(1,73)=684.8, \eta^{2}=.90, p<.001$. To confirm that the randomization procedure resulted in comparable groups, baseline differences were examined using one-way ANOVAs. Results for both self-view groups revealed no significant differences across conditions (for the low self-view group $F(1,33)=1.40, p>.20$; for the high self-view group $F(1,38)=1.58, p>.20)$.

\section{Positive Versus Negative Feedback Seeking: Effects of Self-Views and Evaluation Outcome}

For each of the two evaluation outcome conditions, time spent (in seconds) viewing positive and negative peer feedback is presented in Table 1. To examine our main research question, time spent on positive feedback was entered as the dependent variable into a 2 (Evaluation Outcome) by 2 (Self View Status) ANOVA analysis. Consistent with expectations, a significant interaction effect emerged: $F(1,71)=3.97, p<.05 ; \eta^{2}=.06$. To examine the nature of this interaction effect, simple effects ANOVA analyses were then performed for the two selfview groups separately.

Participants Holding Positive Self-Views: Effects of Evaluation Outcome on Viewing Time

Results for these participants showed that time spent on positive feedback did not differ between the two evaluation 
Table 1 Means and standard deviations for viewing time (seconds) spent on positive and negative feedback by feedback condition and self-view status

\begin{tabular}{|c|c|c|c|c|}
\hline \multirow[t]{3}{*}{ Feedback condition } & \multicolumn{4}{|l|}{ Self view status } \\
\hline & \multicolumn{2}{|l|}{ Positive } & \multirow[b]{2}{*}{ Success $(n=20)$} & \multirow{2}{*}{$\begin{array}{l}\text { Negative } \\
\text { Failure }(n=15)\end{array}$} \\
\hline & Success $(n=20)$ & Failure $(n=20)$ & & \\
\hline \multicolumn{5}{|l|}{ Positive feedback } \\
\hline M & 166.7 & 179.5 & 177.9 & 158.8 \\
\hline SD & 34.8 & 44.4 & 27.8 & 25.2 \\
\hline \multicolumn{5}{|l|}{ Negative feedback } \\
\hline M & 133.3 & 120.5 & 122.1 & 141.2 \\
\hline SD & 34.8 & 44.4 & 27.8 & 25.2 \\
\hline
\end{tabular}

outcome conditions $(F(1,38)=1.03, p>.20)$. Collapsed across both conditions, participants spent significantly more time on positive feedback $(M=173.1 \mathrm{~s})$ than expected by chance (i.e., 150 of the $300 \mathrm{~s}$ viewing time): $t(39)=3.69, p<.001$. These findings are consistent with the expectation that children holding positive self-views would show a robust preference for positive feedback.

\section{Participants Holding Negative Self-Views: Effects of Evaluation Outcome on Viewing Time}

Results showed that time spent on positive feedback was significantly influenced by evaluation outcome; $F(1,34)=$ $4.38, p<.05, d=.72$. Consistent with expectations, children holding negative self-views showed a stronger interest in positive feedback after receiving a self-discrepant positive evaluation outcome than after receiving a self-congruent negative evaluation outcome (see Table 1). Subsequent t-tests showed that, similar to their peers holding positive self-views, children in the success condition spent significantly more time on positive feedback than expected by chance: $t(19)=4.49 ; p<.001$. In contrast, children in the failure condition spent as much time on positive and negative feedback as expected by chance, $p>.20$. Hence, relative to their counterparts in the success condition, children holding negative self-views in the failure condition displayed a stronger, albeit relative preference for negative feedback.

\section{Discussion}

The major aim of the present study was to test the hypothesis that a social success experience leads to reduced self-verification strivings among pre-adolescents holding low levels of global self-esteem. In so doing, we went beyond previous work examining feedback seeking in children in two ways. First, unlike previous studies in which children indicated their preferences for receiving favorable versus unfavorable feedback, participants in the current study actually obtained feedback that was allegedly based on the personal information they had provided to their peer evaluators. Second, we employed an unobtrusive behavioral viewing time measure to address the limitation of previous studies' sole reliance on self-reported feedback preferences.

As predicted, the feedback preferences of children holding negative self-views differed as a function of the valence of the preceding peer evaluation outcome. Specifically, whereas children holding positive self-views displayed a significant preference for positive over negative feedback across the two outcome conditions, children holding negative self-views evidenced a significantly stronger preference for positive feedback after receiving the positive self-discrepant evaluation outcome than after receiving the self-congruent negative evaluation outcome. In fact, after being faced with explicit favorable feedback, these children were as likely as their peers holding positive self-views to display a marked preference for positive feedback. This finding is at odds with a core postulate of self-verification theory stating that negative feedback seeking is driven by a need to verify negative self-views. Self-verification theory would therefore have predicted that after being faced with a self-discrepant favorable evaluation outcome children holding negative self-views display a preference for negative feedback to confirm their feelings of low self-worth.

Overall, the present results with regard to children holding negative self-views are at odds with self-verification theory, and fit better with the view that children holding negative self-views seek more negative feedback only in the context of a negative event that clearly matches their pre-existing unfavorable self-views. However, other studies with children (e.g., Cassidy et al. 2003a, b) have shown that in the absence of a salient evaluative/performance event, children holding negative self-views report a general preference for negative self-verifying feedback. Taken together, contrary to research showing that among adults negative self-views consistently yield a preference for negative self-verifying feedback, it appears that in children the linkage between negative self-views and a preference for negative feedback is less robust. 
One implication of the present findings is that providing low self-esteem children with a salient success experience may be an effective means to circumvent their typical inclination to pass up opportunities to be faced with disconfirming positive information about themselves that may serve to re-evaluate their self-view in a more positive light. Although research has shown that that at some level everyone desires favorable self-enhancing feedback (e.g., Taylor and Brown 1988), we acknowledge that some children holding negative self-views may engage in efforts to discount the positive feedback.

Several features of the present study deserve comment. First, only children's feedback seeking behaviors were assessed, with no attention given to cognitive reactions such as perceptions of the accuracy of the feedback, or the reasons participants provide for their feedback preferences. Second, to maximize the credibility and ecological validity of the feedback seeking procedure, the provided feedback was a mixture of predominantly general feedback with more domain-specific social or physical feedback. Because most of the provided feedback was general in nature, perceived global self-worth served as the index of children's selfviews. However, previous work (e.g., Cassidy et al. 2003a, b) has found differences with respect to specific versus global feedback seeking. Although the somewhat mixed feedback does not seem to compromise the validity of our main finding, namely that children low in global self-worth spend significantly less time viewing negative feedback after being faced with a positive versus a negative peer evaluation outcome, the mixing of general and specific feedback may have affected our results. For instance, it seems possible that a stronger match between the nature of the feedback and our measure of self-views would have yielded stronger differences between the two self-view groups. Third, it should be noted that all participants, including those holding negative self-views who were provided with a negative evaluation outcome, spent more time on positive than on negative feedback. These findings mirror those observed among adults (e.g., Swann et al. 1992). These authors note that "another consequence of the fact that people with negative self-views are motivated to attain favorable as well as unfavorable feedback is that they may sometimes display a relative preference for unfavorable feedback" (p. 301). In the present study, children holding negative self-views faced with negative feedback also displayed only a relative preference for more negative feedback. Specifically, whereas their counterparts in the success condition spent significantly less time on negative than positive feedback, children in the failure condition spent as much time on negative feedback as they did on positive feedback. Finally, this investigation examined children's feedback seeking after being provided a global peer evaluation outcome. Future research is needed to examine the extent to which the present findings extend to children's feedback seeking subsequent to success and failure in other relevant domains (e.g., academics).

Notwithstanding these limitations, the findings from the present study contribute to the limited knowledge base on feedback seeking in children. Most importantly, our findings suggest that when faced with a salient success experience, children holding negative self-views may be apt to preferentially sample positive feedback. As discussed above, research has shown that people holding negative self-views are more likely to display a preference for negative self-verifying feedback when they have more time to reflect on the feedback received. Whereas children holding negative self-views were afforded ample time to realize that the positive feedback contradicted their negative self-views, they still displayed a significant preference for positive over negative feedback.

However, many questions remain. Below we offer several recommendations for advancing research. First, there is a need for more research with children examining selfverification's postulate that those holding strongly positive or strongly negative self-views are preferentially drawn to feedback that confirms their self-conceptions because it engenders feelings of security and control. For instance, future studies could provide children with either self-discrepant or self-confirming feedback and assess their emotional, cognitive and physiological reactions. Second, to assess the effects of more versus less ingrained self-views, research is needed to examine if late adolescents are more likely than middle or early adolescents to display a motivated preference for self-verifying feedback. Finally, future studies should assess if feedback preferences are affected by the characteristics of the people who provide the feedback ("feedback source"). For instance, because children typically segregate into own-gender groups (Maccoby 1998), the gender of the feedback source may exert strong effects on feedback preferences.

Open Access This article is distributed under the terms of the Creative Commons Attribution Noncommercial License which permits any noncommercial use, distribution, and reproduction in any medium, provided the original author(s) and source are credited.

\section{References}

Beck, A. T. (1967). Depression: Clinical, experimental, and theoretical aspects. New York: Harper \& Row.

Borelli, J. L., \& Prinstein, M. J. (2006). Reciprocal, longitudinal associations among adolescents' negative feedback-seeking, depressive symptoms, and peer relations. Journal of Abnormal Child Psychology, 34, 159-169.

Bowlby, J. (1980). Attachment and loss (Vol. 3). New York: Basis Books.

Casbon, T. S., Burns, A. B., Bradbury, T. N., \& Joiner, T. E., Jr. (2005). Receipt of negative feedback is related to increased 
negative feedback seeking among individuals with depressive symptoms. Behaviour Research and Therapy, 43, 485-504.

Cassidy, J., Wargo Aikins, J., \& Jacobson Chernoff, J. (2003a). Children's peer selection: Experimental examination of the role of self-perceptions. Developmental Psychology, 39, 495-508.

Cassidy, J., Ziv, Y., Mehta, T. G., \& Feeney, B. C. (2003b). Feedback seeking in children and adolescents: Associations with selfperceptions, representations, and depression. Child Development, 74, 612-628.

Cole, D. A., Jacquez, F. M., \& Maschman, T. L. (2001). Social origins of depressive cognitions: A longitudinal study of self-perceived competence in children. Cognitive Therapy and Research, 25, 377-395.

Erdfelder, E., Faul, F., \& Buchner, A. (1996). GPOWER: A general power analysis program. Behavior Research Methods, Instruments, \& Computers, 28, 1-11.

Giesler, R. B., Josephs, R. A., \& Swann, W. B., Jr. (1996). Selfverification in clinical depression. Journal of Abnormal Psychology, 105, 358-368.

Harter, S. (1982). The perceived competence scale for children. Child Development, 53, 87-97.

Harter, S. (2006). The self. In W. Damon, R. M. Lerner, \& N. Eisenberg (Eds.), Handbook of child psychology: Vol. 3. Social, emotional, and personality development (pp. 505-570). New York: Wiley.

Hixon, J. G., \& Swann, W. B., Jr. (1993). When does introspection bear fruit? Self-reflection, self-insight, and interpersonal choices. Journal of Personality and Social Psychology, 64, 35-43.

Joiner, T. E., Jr, Katz, J., \& Lew, A. S. (1997). Self-verification and depression among youth psychiatric inpatients. Journal of Abnormal Psychology, 106, 608-618.

Maccoby, E. (1998). The two sexes: Growing up apart, coming together. Cambridge, MA: Harvard University Press.

Reijntjes, A., Dekovic, M., Vermande, M. M., \& Telch, M. J. (2007). Children's feedback preferences in response to an experimentally manipulated peer evaluation outcome: The role of depressive symptoms. Journal of Abnormal Child Psychology, 35, 497-507.

Swann, W. B., Jr. (1983). Self-verification: Bringing social reality into harmony with the self. In J. Suls \& A. G. Greenwald (Eds.),
Psychological perspectives on the self (Vol. 2, pp. 33-66). Hillsdale, NJ: Erlbaum.

Swann, W. B., Jr. (1990). To be adored or to be known: The interplay between self-enhancement and self-verification. In R. M. Sorrentino \& E. T. Higgens (Eds.), Foundations of social behavior (Vol. 2, pp. 408-448). New York: Guilford Press.

Swann, W. B., Jr, Hixon, G., Stein-Seroussi, A., \& Gilbert, D. T. (1990). The fleeting gleam of praise: Behavioral reactions to self-relevant feedback. Journal of Personality and Social Psychology, 59, 17-26.

Swann, W. B., Jr, Rentfrow, P., \& Guinn, J. (2002). Self-verification: The search for coherence. In M. Leary \& J. Tagney (Eds.), Handbook of self and identity (pp. 367-383). New York: Guilford Press.

Swann, W. B., Jr, Stein-Seroussi, A., \& Giesler, R. B. (1992a). Why people self-verify. Journal of Personality and Social Psychology, 62, 392-401.

Swann, W. B., Jr, Wenzlaff, R. M., Krull, D. S., \& Pelham, B. W. (1992b). Allure of negative feedback: Self-verification strivings among depressed persons. Journal of Abnormal Psychology, 101, 293-306.

Swann, W. B., Jr, Wenzlaff, R. M., \& Tafarodi, R. W. (1992c). Depression and the search for negative evaluations: More evidence of the role of self-verification strivings. Journal of Abnormal Psychology, 101, 314-317.

Taylor, S. E., \& Brown, J. D. (1988). Illusion and well-being; a social psychological perspective on mental health. Psychological Bulletin, 103, 193-210.

Thomaes, S., Reijntjes, A., Orobio de Castro, B., Bushman, B. J., Poorthuis, A., \& Telch, M. J. (in press). I like me if you like me: On the interpersonal modulation and regulation of preadolescents' self-esteem. Child Development.

Trzesniewski, K. H., Donnellan, M. B., \& Robins, R. W. (2003). Stability and self-esteem across the life span. Journal of Personality and Social Psychology, 84, 205-220.

Veerman, J. W., Straathof, M. A. E., \& Ten Brink, L. T. (1996). Measuring children's self-concept. Factorial validity and invariance across normal and clinical groups. Journal of Personality Assessment, 67, 142-154. 